INDONESIA ACCOUNTING JOURNAL

VOLUME 1, NUMBER 2, YEAR 2019

${ }^{1}$ Corresponding author

Jurusan Akuntansi

Fakultas Ekonomi dan Bisnis

Universitas Sam Ratulangi

Jl. Kampus UNSRAT

Manado, Indonesia, 95115

E-mail : aditya.damao4o6@gmail.com

${ }^{2,3}$ Jurusan Akuntansi

Fakultas Ekonomi dan Bisnis

Universitas Sam Ratulangi

Jl. Kampus UNSRAT

Manado, Indonesia, 95115

Article info:

Received 8 December 2019

Accepted 9 December 2019

Available online 9 December 2019

Keywords: tax-payers; compliance;

NPWP; income tax

JEL Classification: $\mathrm{H} 24, \mathrm{H} 71$

DOI: http://doi.org/10.3240o/iaj.26638
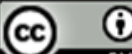

\section{Pengaruh kepemilikan NPWP terhadap kepatuhan wajib pajak pada Kantor Pelayanan Pajak Pratama Manado}

\author{
Aditya Dama ${ }^{1}$ \\ David Paul Elia Saerang ${ }^{2}$ \\ Hendrik Gamaliel ${ }^{3}$
}

\begin{abstract}
Income tax can be used for various functions of determining policies related to income. Taxpayer compliance is strongly influenced by the ownership of a country's NPWP because if a Taxpayer is not compliant it will cause reduced tax revenue. The object of this research is the Income Taxpayer which is limited to the Corporate Income Taxpayer in the city of Manado. The purpose of this study is to determine whether NPWP ownership has an effect on tax compliance at the Manado Primary Tax Service Office. In conducting this research a statistical analysis tool is used that is simple linear regression analysis and is strengthened by testing the hypothesis that is the $t$ test. The results showed the regression model obtained was $\mathrm{Y}=10.895+$ $0.299 \mathrm{X}$. The constant a of 10.895 gives the sense that if the Income Tax Audit is perceived to be constant or equal to zero (o), then the magnitude of Taxpayer Compliance is 10.895 units. Furthermore, the value of $b$ which is a regression coefficient of variable X (NPWP ownership) of 0.299 means that if NPWP ownership has increased by one (1) unit, then the amount of income tax increase has increased or increased by 0.299 units assuming the other variables are fixed or constant. Taxpayers compliance $(\mathrm{Y})$ got contribution from NPWP (X) ownership factor of $6.6 \%$, while the rest was explained by other variables not included in this study. Thus it is known that NPWP ownership has no significant effect on increasing taxpayer compliance.
\end{abstract}

\section{Pendahuluan}

Pajak merupakan pungutan wajib yang dibayar rakyat untuk negara dan akan digunakan untuk kepentingan pemerintah dan masyarakat umum. Penerimaan negara dari sektor pajak merupakan salah satu bentuk partisipasi masyarakat dalam mewujudkan pembangunan. Adapun selain membiayai infrasruktur dan fasilitas umum, dana pajak juga dapat dialokasikan untuk membiayai dana sosial dan membantu pemerintah dalam meningkatkan kualitas sumber daya manusia di segala bidang.

Langkah pemerintah untuk meningkatkan penerimaan dari sektor perpajakan dimulai dengan melakukan reformasi perpajakan secara menyeluruh pada tahun 1983, dan pada awal tahun 1984 sistem perpajakan di Indonesia berubah dari official assessment system menjadi self assessment system. Dalam self assessment system Wajib Pajak lebih dipandang sebagai subjek bukan sebagai objek pajak. Untuk mewujudkan self assessment system dituntut kepatuhan Wajib Pajak itu sendiri. Namun, dalam kenyataannya belum semua potensi pajak yang ada dapat digali sebab masih banyak Wajib Pajak yang belum memiliki kesadaran akan betapa pentingnya pemenuhan kewajiban perpajakan baik bagi negara maupun bagi mereka sendiri sebagai warga negara yang baik.

Dalam kondisi tersebut keberadaan self assessment system memungkinkan Wajib Pajak untuk melakukan kecurangan pajak. Tanpa adanya penelitian dan pemeriksaan pajak serta tidak adanya ketegasan dari instansi pajak, maka ketidakpatuhan Wajib Pajak 
tersebut dapat berkembang sedemikian rupa sehingga bisa mencapai suatu tingkat dimana sistem perpajakan akan menjadi lemah. Berdasarkan survei tentang penerimaan pajak yang telah dihimpun oleh Badan Pusat Statistik Republik Indonesia, dikatakan bahwa setiap tahunnya terjadi peningkatan penerimaan pajak. Dalam hal ini pemerintah telah mengambil langkah-langkah kebijakan agar dapat memancing kesadaran masyarakat untuk membayar pajak demi memaksimalkan penerimaan pajak. Sebelum membuat kebijakan-kebijakan tersebut, ada beberapa hal yang harus diketahui oleh pemerintah sebagai pembuat kebijakan. Faktor-faktor yang dapat mempengaruhi penerimaan pajak diantaranya pemerintah, petugas pajak (fiskus), dan masyarakat yang berperan penting dalam upaya mengoptimalkan penerimaan pajak.

Sesuai dengan ketentuan peraturan perundang-undangan perpajakan berdasarkan sistem self assessment, semua wajib pajak yang telah memenuhi persyaratan subjektif dan objektif wajib mendaftarkan diri pada Kantor Direktorat Jenderal Pajak untuk dicatat sebagai wajib pajak dan sekaligus untuk mendapatkan Nomor Pokok Wajib Pajak (NPWP). Persyaratan objektif adalah persyaratan bagi subjek pajak yang menerima atau memperoleh penghasilan atau yang diwajibkan untuk melakukan pemotongan/pemungutan sesuai UndangUndang Nomor 28 tahun 2007 tentang ketentuan umum dan tata cara perpajakan pasal 2 ayat (1) UU KUP. Pengesahan pemberian NPWP dilakukan dengan pemberian Surat Keterangan Terdaftar. Surat tersebut menginformasikan pemenuhan kewajiban perpajakan kepada setiap wajib pajak. Berdasarkan hasil penelitian petugas Seksi Tata Usaha Perpajakan, kewajiban perpajakan tersebut diisi dan harus dilaksanakan oleh setiap wajib pajak. Pengisian kewajiban perpajakan harus didasarkan pada ketentuan peraturan perundang-undangan perpajakan yang berlaku, sehingga pelaksanaan atas kewajiban perpajakan oleh setiap wajib pajak dapat mengamankan penerimaan pajak.
Semakin banyak isian kewajiban perpajakan oleh wajib pajak secara benar dan tepat, maka penerimaan pajak meningkat. Pada tahun 2018 di bulan Februari Kantor DJP Manado telah menerbitkan NPWP Badan sebanyak 8.383 dan NPWP Orang Pribadi sebanyak 94.668 yang menunjukkan semakin patuhnya masyarakat Sulawesi Utara atas kewajiban perpajakan. Berdasarkan uraian ini, maka tujuan penelitian ini adalah untuk mengetahui pengaruh kepemilikan NPWP terhadap kepatuhan wajib pajak pada KPP Pratama Manado.

\section{Tinjauan pustaka}

Pajak. Pajak adalah salah satu sumber penerimaan negara yang pokok, membiayai keperluan-keperluan Negara. Soemitro dalam Mardiasmo (2011:1), pajak adalah iuran rakyat kepada kas negara berdasarkan undang-undang (yang dapat dipaksakan) dengan tiada mendapat jasa timbal (kontra prestasi) yang langsung dapat di tunjukan dan yang digunakan untuk membayar pengeluaran umum. Waluyo dan Ilyas (2009.2) menyatakan bahwa pajak adalah iuran masyarakat kepada negara yang terutang oleh yang wajib membayarnya menurut peraturan-peraturan umum (Undang-Undang) dengan tidak mendapat prestasi kembali yang langsung dapat ditunjuk dan yang gunanya adalah untuk membiayai pengeluaran-pengeluaran umum berhubung tugas negara untuk menyelenggarakan pemerintahan. Mardiasmo (2011:1) menyatakan Pajak adalah iuran rakyat kepada kas negara berdasarkan undang-undang (yang dapat dipaksakan) dengan tiada mendapat jasa tibal (kontra prestasi), yang langsung dapat ditujukan dan digunakan untuk membayar pengeluaran Umum.

Fungsi pajak. Menurut Mardiasmo (2011:1), pajak memiliki 2 (dua) fungsi, yaitu : (1) fungsi Budgetair atau pajak sebagai sumber dana bagi pemerintah dalam membiayai penyelenggaraan Negara; dan (2) fungsi mengatur (regulerend) atau pajak digunakan untuk mengatur atau melaksanakan kebijaksanaan pemerintah dalam bidang sosial dan ekonomi. 
Penghasilan Tidak Kena Pajak (PTKP). Merupakan penghasilan sampai jumlah tertentu yang tidak dikenai pajak karena digunakan oleh Wajib Pajak untuk memenuhi kebutuhan dasarnya agar dapat bekerja untuk mendapatkan penghasilan yang akan menjadi objek pajak (Mardiasmo, 2011:1). Peraturan Menteri Keuangan (PMK) Nomor 101/PMK.010/2016 tentang Penyesuaian Besarnya Penghasilan Tidak Kena Pajak mengatur bahwa setiap Wajib Pajak memiliki PTKP sebesar Rp 54 juta setahun dan apabila berstatus kawin akan mendapatkan tambahan sebesar Rp 4,5 juta setahun. Berdasarkan batasan penghasilan ini, maka apabila seorang yang bekerja memiliki penghasilan (gaji dan lain-lain) dalam satu tahun melebihi PTKP, maka orang tersebut wajib mendaftarkan diri sebagai Wajib Pajak untuk memperoleh Nomor Pokok Wajib Pajak (NPWP). Apabila seorang seorang pekerja memperoleh penghasilan diatas PTKP tetapi belum mempunyai NPWP, maka atas penghasilan tersebut akan dikenakan Pajak Penghasilan dengan tarif lebih tinggi yaitu sebesar $20 \%$ (dua puluh persen) lebih tinggi dari tarif pajak penghasilan.

Nomor Pokok Wajib Pajak (NPWP). Pengertian Nomor Pokok Wajib Pajak (NPWP) sebagaimana yang tertera dalam Undang-Undang Nomor 28 Tahun 2007 tentang Ketentuan Umum dan Tata Cara Perpajakan Pasal 1 ayat 6 menjelaskan bahwa NPWP adalah nomor yang diberikan kepada Wajib Pajak sebagai sarana dalam administrasi perpajakan yang dipergunakan sebagai tanda pengenal diri atau identitas Wajb Pajak dalam melaksanakan hak dan kewajiban perpajakannya. Pendapat yang sama, Resmi (2014.24) mengemukakan bahwa NPWP merupakan suatu sarana dalam administrasi perpajakan yang dipergunakan sebagai tanda pengenal diri atau identitas wajib pajak. Diana dan Setiawati (2009:4) menyatakan bahwa semua wajib pajak yang telah memenuhi persyaratan subjektif dan objektif sesuai ketentuan peraturan perundang-undangan perpajakan berdasarkan sistem self assessment, wajib mendaftarkan diri pada Kantor
Direktorat Jenderal Pajak untuk dicatat sebagai wajib pajak dan sekaligus untuk mendapatkan NPWP. Lebih lanjut, Diana dan Setiawati (2009:4) menyatakan bahwa persyaratan objektif adalah persyaratan bagi subjek pajak yang atau memperoleh penghasilan atau yang diwajibkan sesuai ketentuan yang berlaku.

Sanksi tidak memiliki NPWP. Bagi warga negara yang sudah memenuhi ketentuan perpajakan tetapi tidak mendaftarkan diri untuk mendapatkan NPWP akan dikenakan sanksi sesuai Undang-Undang No. 28 Tahun 2007, berupa: (1) pidana penjara paling singkat 6 bulan dan paling lama 6 tahun; dan (2) denda senilai dua kali jumlah pajak terutang yang tidak atau kurang dibayar, dan paling banyak empat kali jumlah pajak terutang yang tidak atau kurang dibayar.

Penghapusan NPWP dan persyaratannya. Tansuria (2010:8) menjelaskan bahwa penghapusan Nomor Pokok Wajib Pajak dilakukan oleh Direktur Jenderal Pajak apabila memenuhi syarat sebagai berikut yaitu: (1) wajib pajak sudah tidak memenuhi persyaratan subjektif dan/atau objektif, misalnya wajib pajak orang pribadi meninggal dunia dan tidak meninggalkan warisan; (2) wajib pajak badan dalam rangka likuidasi atau pembubaran karena penghentian atau penggabungan usaha; (3) wanita yang sebelumnya telah memiliki NPWP dan menikah tanpa membuat perjanjian pemisahan harta dan penghasilan; (4) wajib pajak bentuk badan usaha tetap yang menghentikan usahanya di Indonesia; dan (5) warisan yang belum terbagi dalam kedudukan sebagai Subjek Pajak sudah selesai dibagi.

Penelitian terdahulu. Simanungkalit et al. (2015), Pamber (2016), dan Jannata et al. (2019) menemukan bahwa kepemilikan NPWP tidak signifikan atas penerimaan pajak. Menurut Gunawan (2016), Riesvie (2016), Yuliyanti (2018), Dharmayanti dan Humayroh (2019), dan Ernawati et al. (2019) menemukan bahwa kepemilikan NPWP signifikan atas kepatuhan wajib pajak. 
Hipotesis. Berdasarkan kajian penelitian terdahulu, maka hipotesis penelitian ini adalah diduga Kepemilikan NPWP (X) berpengaruh terhadap Kepatuhan Wajib Pajak (Y) pada KPP Pratama Manado.

\section{Metode penelitian}

Jenis Penelitian. Penelitian ini menggunakan pendekatan kuantitatif dengan jenis analisis deskriptif. Jenis penelitian ini digunakan untuk dapat menganalisis dan memahami pengaruh kepemilikan NPWP terhadap kepatuhan wajib pajak di Kantor Pelayanan Pajak Pratama Manado.

Sampel. Penelitian ini menetapkan sampel dengan menggunakan metode survey. Sehingga sampel yang diambil dalam penelitian ini adalah Wajib pajak badan yang ada di Manado. Jumlah sampel yang diambil adalah sebanyak 30 sampel dengan metode random sampling. Random sampling adalah cara pengambilan sampel yang memberikan kesempatan yang sama untuk diambil kepada setiap elemen populasi.

\section{Definisi dan pengukuran variabel}

1. Kepemilikan NPWP (X). Variabel ini diukur dengan Skala Likert 1 sampai dengan 5 (Sangat Tidak Setuju hingga Sangat Setuju) dimana penggunaan kuesioner yang disebarkan menggunakan 5 (lima) pertanyaan sebagai berikut:

1. Wajib pajak dapat membayar dan melaporkan pajak dengan tertib.

2. Wajib pajak terhindar dari pengenaan sanksi karena tidak memiliki NPWP.

3. Wajib pajak terhindar dari tarif Pajak Penghasilan yang lebih tinggi.

4. Wajib pajak akan memperoleh kemudahan pengajuan izin usaha.

5. Wajib pajak akan memperoleh kemudahan pelayanan perpajakan.

2. Kepatuban wajib pajak (Y). Kepatuhan Wajib Pajak adalah suatu kondisi di mana wajib pajak mengetahui, mengakui, menghargai dan menaati ketentuan perpajakan yang berlaku serta memiliki kesungguhan dan keinginan untuk memenuhi kewajiban pajaknya. Variabel ini diukur dengan Skala Likert 1 sampai dengan 5 (Sangat Tidak Setuju hingga Sangat Setuju) dimana penggunaan kuesioner yang disebarkan menggunakan 5 (lima) pertanyaan sebagai berikut:

1. Bagi saya, melakukan ketidakpatuhan Pajak adalah hal yang sulit.

2. Keputusan untuk melakukan ketidakpatuhan pajak berada dalam kendali saya.

3. Melakukan ketidakpatuhan pajak sepenuhnya terserah saya.

4. Menurut saya, ketidakpatuhan pajak merupakan tindakan yang tidak merugikan pihak lain.

5. Saya tidak merasakan bersalah ketika saya melakukan ketidakpatuhan pajak.

Metode analisis. Analisis regresi linear sederhana adalah regresi linear sederhana yang hanya menggunakan data variabel yang digunakan untuk mengetahui ada tidaknya pengaruh variabel $\mathrm{X}$ terhadap variabel $\mathrm{Y}$. Bentuk persamaan regresi sederhana dalam penelitian ini adalah :

$$
\mathrm{Y}=\alpha+\beta \mathrm{X}
$$

Dimana $X$ adalah Kepemilikan NPWP dan Y adalah kepatuhan wajib pajak.

Uji hipotesis (Uji t). Selanjutnya untuk menguji hipotesis yang diajukan, maka digunakan statistik Uji t. Uji t adalah untuk menguji pengaruh variabel bebas secara parsial atau sendiri-sendiri dengan kriteria pengujian, jika t hitung $>$ t tabel maka $\mathrm{Ho}$ ditolak, berarti $\mathrm{Ha}$ diterima atau dengan menggunakan kriteria lain yaitu apabila signifikan $<0,05$ maka Ho ditolak, Ha diterima atau apabila signifikan $>0,05$ maka Ho diterima, Ha ditolak.

\section{Hasil penelitian dan pembahasan}

\section{Hasil penelitian}

Deskripsi umum responden. Tabel 1 menggambarkan kondisi responden berdasarkan pekerjaan. Tabel 1 menunjukkan bahwa responden yang berasal dari pengusaha merupakan responden terbanyak dengan jumlah 12 orang dengan persentase $40 \%$ dari jumlah responden, 
sedangkan responden paling sedikit adalah pegawai negeri dengan jumlah masingmasing 4 orang responden dengan persentase $13,3 \%$.

Tabel 1. Distribusi responden berdasarkan pekerjaan

\begin{tabular}{lcc}
\hline \multicolumn{1}{c}{ Pekerjaan } & $\begin{array}{c}\text { Jumlah } \\
\text { Responden }\end{array}$ & Persentase (\%) \\
\hline Pengusaha & 12 orang & $40 \%$ \\
Pegawai Swasta & 9 orang & $30 \%$ \\
Pegawai Negeri & 5 orang & $16,6 \%$ \\
Lain-lain & 4 orang & $13,3 \%$ \\
\hline Jumlah & $\mathbf{3 0}$ orang & $\mathbf{1 0 0 \%}$ \\
\hline Sumber: Data Olahan, 2019 & &
\end{tabular}

Tabel 2 menunjukkan bahwa data responden kelompok umur 40 - 55 tahun merupakan responden dengan kelompok terbesar dengan jumlah 11 orang dengan Persentase $36,6 \%$ dari jumlah responden, umur $>56$ tahun berjumlah 10 orang atau $33,3 \%$, sedangkan paling sedikit adalah kelompok umur 25-39 tahun dengan jumlah masing-masing responden orang dengan persentase $30 \%$.

Tabel 2. Distribusi responden berdasarkan kelompok umur

\begin{tabular}{lcc}
\hline Kelompok Umur & $\begin{array}{c}\text { Jumlah } \\
\text { Responden }\end{array}$ & Persentase (\%) \\
\hline $25-39$ tahun & 9 orang & $30 \%$ \\
$40-55$ tahun & 11 orang & $36,6 \%$ \\
$>56$ & 10 orang & $33,3 \%$ \\
\hline Jumlah & $\mathbf{3 0}$ orang & $\mathbf{1 0 0 \%}$ \\
\hline Sumber $:$ Data Olahan, 2019 & &
\end{tabular}

\section{Koefisien korelasi (R) dan} determinasi $\left(\mathbf{R}^{2}\right)$. Tabel 3 menunjukkan bahwa nilai koefisien korelasi masing-masing variabel bebas yaitu untuk X (Kepemilikan NPWP) adalah 0,257 artinya hubungan variabel Kepemilikan NPWP guna meningkatkan kepatuhan wajib pajak positif atau dapat dikatakan mempunyai hubungan. Koefisien determinasi adalah 0.066 atau model kepatuhan wajib pajak dapat dijelaskan sebesar $6.6 \%$ oleh kepemilikan NPWP.

\begin{tabular}{|c|c|c|c|c|}
\hline Model & $\mathbf{R}$ & $\begin{array}{c}\mathbf{R} \\
\text { Square }\end{array}$ & $\begin{array}{c}\text { Adjusted R } \\
\text { Square }\end{array}$ & $\begin{array}{l}\text { Std. Error of the } \\
\text { Estimate }\end{array}$ \\
\hline 1 & $0.257^{\mathrm{a}}$ & 0.066 & 0.033 & 2.52196 \\
\hline
\end{tabular}

\section{Pembahasan}

Tabel 4 menyajikan hasil pengolahan data dengan menggunakan bantuan program
SPSS Version 18. Persamaan regresi dari penelitian ini adalah :

$$
\mathrm{Y}=10,895+0,299 \mathrm{X}
$$

Tabel 4. Hasil uji regresi sederhana

\begin{tabular}{|c|c|c|c|c|c|c|}
\hline \multirow{3}{*}{\multicolumn{2}{|c|}{ Model }} & \multicolumn{2}{|c|}{$\begin{array}{l}\text { Unstandardized } \\
\text { Coefficients }\end{array}$} & \multirow{3}{*}{$\begin{array}{c}\text { Standardized } \\
\text { Coefficients } \\
\text { Beta } \\
\end{array}$} & \multirow[b]{3}{*}{$t$} & \multirow[b]{3}{*}{ Sig. } \\
\hline & & & Std. & & & \\
\hline & & B & Error & & & \\
\hline \multirow[t]{2}{*}{1} & (Constant) & 10.895 & 2.881 & & 3.782 & 0.001 \\
\hline & $\mathrm{X}$ & 0.299 & 0.212 & 0.257 & 1.408 & 0.170 \\
\hline
\end{tabular}

Berdasarkan hasil analisis regresi sederhana, diketahui bahwa variabel $\mathrm{X}$ memiliki koefisien positif. Hal ini mengindikasikan bahwa adanya kepemilikan NPWP cenderung meningkatkan kepatuhan wajib pajak. Hasil analisis regresi juga membuktikan bahwa koefisien variabel $\mathrm{X}$ (Kepemilikan NPWP) adalah 1,408 dimana $\mathrm{t}$ tabel adalah 2,048, sehingga karena t hitung $<\mathrm{t}$ tabel maka H0 ditolak berarti $\mathrm{Ha}$ diterima artinya kepemilikan NPWP berpengaruh tidak signifikan terhadap Peningkatan Kepatuhan Wajib Pajak. Hasil penelitian ini tidak mendukung hasil penelitian dari Gunawan (2016), Riesvie (2016), Yuliyanti (2018), Dharmayanti dan Humayroh (2019), dan Ernawati et al. (2019) menemukan bahwa kepemilikan NPWP signifikan atas kepatuhan wajib pajak.

\section{Kesimpulan dan saran \\ Kesimpulan}

Dari hasil pembahasan maka kesimpulan atas penelitian ini adalah:

1. Pengaruh Kepemilikan NPWP terhadap Kepatuhan wajib Pajak berpengaruh tidak signifikan, berdasarkan penelitian ini kontribusi variabel independen $(\mathrm{X})$ untuk menjelaskan model variabel dependan $(Y)$ sangat lemah.

2. Kepatuhan Wajib Pajak memberikan kontribusi yang penting dalam perpajakan dimana wajib pajak dapat memenuhi kewajibanya sesuai dengan aturan yag berlaku sehingga semua proses perpajakan dapat berjalan sebagaimana mestinya. KPP Pratama Manado sudah menggunakan system komputerisasi dan integrasi dalam 
melakukan pendataan objek pajak, melakukan sosialisasi kepada masyarakat tentang manfaat dan tujuan dari $\mathrm{PPh}$ serta pelayanan pendataan objek dan subjek pajak dilakukan petugas dengan efektif.

3. Kepatuhan Wajib Pajak (Y) mendapat kontribusi dari faktor Kepemilikan NPWP (X) pada Kantor Pelayanan Pajak Pratama Manado tersebut sebesar 6,6\% sedangkan sisanya dijelaskan oleh variabel lain yang tidak dimasukan dalam penelitian ini. Dengan demikian diketahui bahwa Kepemilikan NPWP berpengaruh tidak signifikan terhadap Kepatuhan Wajib Pajak.

\section{Saran}

Saran atas penelitian ini adalah:

1. Bagi KPP Pratama Manado, diharapkan dapat melakukan pemeriksaan pajak dengan baik, profesional dan sesuai dengan undang undang yang berlaku agar wajib dapat bertanggung jawab terhadap kewajiban perpajakanya.

2. Hasil penelitian ini diharapkan dapat memberikan masukkan kepada pihakpihak yang terkait dengan pemungutan $\mathrm{PPh}$ agar lebih selalu memberikan pelayanan yang prima kepada Wajib Pajak.

3. Kiranya penelitian ini dapat menjadi acuan untuk penelitian-penelitian yang akan datang, baik berkaitan dengan penelitian ini secara langsung maupun secara tidak langsung.

\section{Daftar pustaka}

Dharmayanti, N., \& Humayroh, S. A. (2019). Pengaruh NPWP dan sanksi perpajakan terhadap kepatuhan wajib pajak (Studi Kasus Civitas Akademika Universitas Islam Syekh-Yusuf Tangerang). Ekonomi Bisnis, 25(1), 32-46. https://doi.org/10.33592/jeb.v25i1.286

Diana, A., \& Setiawati, L. (2009). Perpajakan Indonesia. Yogyakarta: Penerbit Andi.

Gunawan, N. A. (2016). Pengarub Kepemilikean NPWP, Pengetabuan Wajib Pajak, dan Sanksi Pajak terbadap Kepatuban Wajib Pajak Orang Pribadi (Studi Kasus pada KPP Pratama Bandung Bojonagara). Skripsi: Universitas Kristen Maranatha. https://repository.maranatha.edu/21667/

Ernawati, E., Yuniati, Y., \& Rustandi, R. (2019). Pengaruh pengetahuan pajak dan kepemilikan NPWP terhadap kepatuhan wajib pajak orang pribadi melalui religiusitas sebagai variabel intervening. Jurnal Ilmiah MEA (Manajemen, Ekonomi, \& Akuntansi), 3(2), 121-133. http://journal.stiemb.ac.id/index.php/mea/artic le/view/178

Jannata, R. A., Nurhayati, N., \& Halimatusadiah, E. (2019). Pengaruh kewajiban kepemilikan NPWP dan pemeriksaan pajak terhadap ukuran penerimaan pajak penghasilan badan (Survey pada seluruh petugas pajak di Kantor Pelayanan Pajak Pratama Soreang). Kajian Akuntansi, 20(1), 58-64. https://doi.org/10.29313/ka.v21i2.4502

Mardiasmo. (2011). Perpajakan, Edisi Revisi. Yogyakarta: Penerbit Andi.

Pamber, S. (2016). Pengaruh kepemilikan NPWP, pemeriksaan pajak dan penagihan pajak terhadap penerimaan pajak (Studi pada Kantor Pelayanan Pajak Pratama Pekanbaru Tampan). Jurnal Mahasiswa Prodi Akuntansi Fakultas Ekonomi, 2(2), 1-14. $\quad$ http://ejournal.upp.ac.id/index.php/akfekon/article/vie w/968

Peraturan Menteri Keuangan (PMK) Nomor 101/PMK.010/2016 tentang Penyesuaian Besarnya Penghasilan Tidak Kena Pajak.

Resmi, S. (2014). Perpajakan Teori dan Kasus Edisi 4. Jakarta: Salemba Empat.

Riesvie, A. (2016). Pengaruh kemanfaatan NPWP, pemabaman wajib pajak, kualitas pelayanan, dan sanksi perpajakan terhadap kepatuhan wajib pajak orang pribadi di KPP Pratama Batu. Skripsi: Jurusan Akuntansi Fakultas Ekonomi Universitas Negeri Malang. http://akuntansi.fe.um.ac.id/en/index.php/201 6/08/30/pengaruh-kemanfaatan-npwppemahaman-wajib-pajak-kualitas-pelayanan-dansanksi-perpajakan-terhadap-kepatuhan-wajibpajak-orang-pribadi-di-kpp-pratama-batu/

Simanungkalit, A., Poputra, A., \& Runtu, T. (2015). Pengaruh kewajiban kepemilikan NPWP, pemeriksaan pajak dan penagihan pajak terhadap penerimaan pajak (Studi Kasus pada KPP Pratama Bitung). Going Concern : Jurnal Riset Akuntansi, 10(4), 1-9. https://doi.org/10.32400/gc.10.4.10514.2015

Tansuria, B. I. (2010). Pokok-Pokok Ketentuan Umum Perpajakan, Edisi Pertama. Yoyakarta: Graha Ilmu.

Undang-Undang Nomor 28 Tahun 2007 tentang Ketentuan Umum dan Tata Cara Perpajakan.

Waluyo dan Ilyas, W. B. (2009). Perpajakan Indonesia. Jakarta: Salemba Empat.

Yuliyanti, C. D. (2018). Pengaruh kemanfaatan NPWP, pemahaman wajib pajak, dan kesadaran wajib pajak terhadap kepatuhan wajib pajake (Studi Kasus UMKM di Kota Surakarta). Skripsi: Program Studi Akuntansi Jurusan Pendidikan Akuntansi Fakultas Ekonomi Universitas Negeri Yogyakarta. http://eprints.uny.ac.id/62164/1/R.\%20A.\%20 CITRA\%20DEWI\%20YULIYANTI.pdf 